\title{
Promotion of tumorigenesis by heterozygous disruption of the beclin 1 autophagy gene
}

\author{
Xueping Qu, ${ }^{1}$ Jie Yu, ${ }^{1}$ Govind Bhagat, ${ }^{2}$ Norihiko Furuya, ${ }^{1}$ Hanina Hibshoosh, ${ }^{2}$ \\ Andrea Troxel, ${ }^{3}$ Jeffrey Rosen, ${ }^{4}$ Eeva-Liisa Eskelinen, ${ }^{5}$ Noboru Mizushima, $, 6,7$ \\ Yoshinori Ohsumi, ${ }^{6}$ Giorgio Cattoretti, ${ }^{2,8}$ and Beth Levine ${ }^{1}$ \\ ${ }^{1}$ Department of Medicine, \\ ${ }^{2}$ Department of Pathology, \\ ${ }^{3}$ Department of Biostatistics, and Mailman School of Public Health, Columbia University, New York, New York, USA \\ ${ }^{4}$ Department of Molecular and Cellular Biology and Department of Medicine, Baylor College of Medicine, \\ Houston, Texas, USA \\ ${ }^{5}$ Institute of Biochemistry, University of Kiel, Kiel, Germany \\ ${ }^{6}$ Department of Cell Biology, National Institute of Basic Biology, Okazaki, Japan \\ ${ }^{7}$ Precursory Research for Embryonic Science and Technology (PRESTO), Japan Science and Technology Corp., \\ Kawaguchi, Japan \\ ${ }^{8}$ Institute for Cancer Genetics, Columbia University, New York, New York, USA
}

\begin{abstract}
Malignant cells often display defects in autophagy, an evolutionarily conserved pathway for degrading long-lived proteins and cytoplasmic organelles. However, as yet, there is no genetic evidence for a role of autophagy genes in tumor suppression. The beclin 1 autophagy gene is monoallelically deleted in $40-75 \%$ of cases of human sporadic breast, ovarian, and prostate cancer. Therefore, we used a targeted mutant mouse model to test the hypothesis that monoallelic deletion of beclin 1 promotes tumorigenesis. Here we show that heterozygous disruption of beclin 1 increases the frequency of spontaneous malignancies and accelerates the development of hepatitis B virus-induced premalignant lesions. Molecular analyses of tumors in beclin 1 heterozygous mice show that the remaining wildtype allele is neither mutated nor silenced. Furthermore, beclin 1 heterozygous disruption results in increased cellular proliferation and reduced autophagy in vivo. These findings demonstrate that beclin 1 is a haplo-insufficient tumor-suppressor gene and provide genetic evidence that autophagy is a novel mechanism of cell-growth control and tumor suppression. Thus, mutation of beclin 1 or other autophagy genes may contribute to the pathogenesis of human cancers.

This article was published online in advance of the print edition. The date of publication is available

from the JCI website, http://www.jci.org. J. Clin. Invest. 112:1809-1820 (2003). doi:10.1172/JCI200320039.
\end{abstract}

\section{Introduction}

Normal cell growth requires a well-coordinated balance between the cell's biosynthetic machinery (e.g., protein synthesis and organelle biogenesis) and its degradative processes (e.g., protein degradation and organelle turnover). The ubiquitin-proteasome system (a nonlysosomal pathway) is the major cellular route for the degradation of short-lived proteins, whereas autophagy (a lysosomal pathway) is the major cellular route for the degradation of long-lived proteins and cytoplasmic organelles. In recent years, evidence has been accumulating that alterations of ubiquitin-medi-

Received for publication September 15, 2003, and accepted in revised form October 30, 2003.

Address correspondence to: Beth Levine, Department of Medicine, P \& S 8-463, Columbia University College of Physicians and Surgeons, 630 West 168th Street, New York, New York 10032, USA. Phone: (212) 305-7312; Fax: (212) 305-7290;

E-mail: levine@cancercenter.columbia.edu.

Conflict of interest: The authors have declared that no conflict of interest exists.

Nonstandard abbreviations used: hepatitis B virus (HBV); thyroid transcription factor-1 (TTF-1); peanut agglutinin (PNA); diffuse large-cell lymphoma (DLCL); immunoblastic DLCL (DLCL-IB); terminal end bud (TEB). ated proteolysis of cell cycle regulators contribute to tumorigenesis, either by defective degradation of positive cell cycle regulators or by enhanced degradation of negative cell cycle regulators (reviewed in ref. 1). As a result, the ubiquitin-proteasome pathway is now being targeted in efforts to develop new treatments for cancer (reviewed in refs. 2-4). In contrast, little attention has been devoted to understanding the role of autophagy in cancer biology, even though some agents with known antitumor activity (e.g., tamoxifen and rapamycin) are potent inducers of autophagy $(5,6)$.

Autophagy is a dynamic process involving the rearrangement of subcellular membranes to sequester cytoplasm and organelles for delivery to the lysosome, where the sequestered cargo is degraded and recycled (reviewed in refs. 7, 8). The process of autophagy permits cells to survive during environmental starvation; enables cells to undergo structural remodeling during differentiation and development; and prevents aging, possibly through its housekeeping effects of removing damaged organelles. The deregulation of autophagy contributes to the pathogenesis of different disease states, including neurodegenerative disorders, cardiomyopathy, skeletal myopathies, $\alpha_{1}$-antitrypsin deficiency, and infectious 
diseases (reviewed in ref. 9). Moreover, there is often an inverse relationship between autophagic activity and malignant potential, raising the possibility that defects in cellular autophagy contribute to the development of cancer. Specifically, malignant or transformed cells often display lower basal autophagic activity than their normal counterparts and do not show increased autophagic protein degradation rates in response to serum deprivation or high cell density (10-13). In rat liver carcinogenesis models, autophagic activity is mildly reduced at a preneoplastic stage and becomes more substantially diminished in primary hepatocellular tumor cells (14). However, it is not known whether the decrease in autophagy observed in malignant cells is mechanistically important in tumorigenesis or merely an epiphenomenon associated with malignant transformation.

The identification of several genes required for autophagy provides the opportunity to use genetic approaches to investigate the role of autophagy defects in the development of cancer. Genetic screens in yeast have identified a set of evolutionarily conserved genes known as the apg or aut genes - that are essential for the execution of autophagy $(15,16)$. Previously, we identified Beclin 1 (17), the mammalian homolog of yeast Apg6/Vps30p (18), and demonstrated that beclin 1 complements autophagy in yeast disrupted of APG6/VPS30 and promotes starvation-induced autophagy in MCF7 human breast carcinoma cells (19). As part of a class III PI3K complex, Beclin 1 is thought to be important in mediating the localization of other autophagy proteins to pre-autophagosomal structures (20).

The beclin 1 gene maps to a tumor-susceptibility locus on human chromosome $17 \mathrm{q} 21$ that is monoallelically deleted in up to $75 \%$ of ovarian cancers (21-24), $50 \%$ of breast cancers $(25,26)$, and $40 \%$ of prostate cancers $(27)$, raising the possibility that it may be a tumor suppressor. However, biallelic inactivations of beclin 1 have not been demonstrated in human cancers, and therefore, as yet, the gene does not fulfill the Knudson two-hit hypothesis (28) for classification as a tumor suppressor. For example, in a mutational analysis of breast cancer cell lines with net beclin 1 deletions, no mutations were found in the coding regions or splice junctions of remaining alleles, and Northern blot analysis did not identify abnormalities in beclin 1 transcripts (29).

Even though biallelic mutations of beclin 1 have not been demonstrated in human cancer, three lines of evidence suggest that decreased Beclin 1 protein expression may contribute to mammary tumorigenesis. First, Beclin 1 protein is expressed in all normal breast epithelial cells, but the levels of the protein are frequently low or undetectable in malignant breast epithelial cells (19). Second, the autophagy-promoting effects of beclin 1 gene transfer in MCF7 human breast carcinoma cells are associated with tumor-suppressor function $(19,30)$. In these cells, inducible expression of wild-type Beclin 1, but not an autophagy-defective nuclear export signal mutant of Beclin 1, leads to the loss of malignant morphologic properties, decreased rate of cell proliferation, impaired clonogenicity in vitro, and reduced ability to form tumors in nude mice. Third, Beclin 1 expression and autophagy in MCF7 cells can be induced by tamoxifen (31), an antiestrogen compound that is widely used in the chemoprevention and treatment of breast cancer.

Based on these observations, coupled with the lack of documented biallelic mutations of beclin 1 in human cancer, we hypothesized that beclin 1 is a haplo-insufficient tumor-suppressor gene. In this study, we demonstrate that heterozygous disruption of beclin 1 results in increased spontaneous tumorigenesis, accelerated hepatitis $\mathrm{B}$ virus-induced (HBV-induced) neoplasia, increased cellular proliferation, and reduced autophagy in mice. These findings suggest a fundamental role for the beclin 1 autophagy gene in negative cell growth control and tumor suppression.

\section{Methods}

Mice. A 129Sv/J genomic bacterial artificial chromosome (BAC) library (Genome Systems Inc., St. Louis, Missouri, USA) was screened with a mouse beclin 1 cDNA fragment to isolate a BAC clone (no. 20463) containing the entire mouse beclin 1 gene. The targeting vector was generated by ligation of a $5^{\prime}$ arm $(5.7-\mathrm{kb}$ fragment upstream of exon 1 of beclin 1) and a $3^{\prime}$ arm (0.8-kb fragment within intron 2 of beclin 1) flanking a neomycin resistance cassette (PPGK neo) into the vector, pSP72 (Promega Corp., Madison, Wisconsin, USA). The targeting vector was linearized by NotI and electroporated into 129Sv/J ES cells. Correct targeting resulted in the replacement of beclin 1 exons 1 and 2 by the neomycin resistance gene and was verified by PCR and Southern blot analysis. Chimeric mice were produced by microinjection of correctly targeted ES cells into C $57 \mathrm{BL} / 6 \mathrm{~J}$ blastocysts. Chimeric males were mated with C57BL/6J females, and germ-line transmission of the mutated allele was verified by PCR and Southern blot analysis of tail DNA from $\mathrm{F}_{1}$ offspring. All mice studied for spontaneous tumor development were the $\mathrm{F}_{2}$ generation of $129 \mathrm{~Sv} / \mathrm{J} \times \mathrm{C} 57 \mathrm{BL} / 6 \mathrm{~J}$ crosses. Wild-type littermates were used as controls for beclin 1 heterozygous-deficient mice and sacrificed at identical time points for histopathologic analyses. Note that there is no reported increase in the incidence of any of the tumor types observed in our study in either $129 \mathrm{~Sv} / \mathrm{J}$ or C57BL/6J genetic strains (32), suggesting that strainspecific modifiers are unlikely to account for phenotypic differences observed between the beclin $1^{+/-}$and beclin $1^{+/+} \mathrm{F}_{2}$ littermates in this study. For studies of hepatocellular carcinogenesis, $129 \mathrm{~Sv} / \mathrm{J} \times \mathrm{C} 57 \mathrm{BL} / 6 \mathrm{~J} \mathrm{~F}_{2}$ males were crossed with C57BL/ 6 female mice of the 50-4 lineage (33) that transgenically express the HBV large-envelope polypeptide under the transcriptional control of the mouse albumin promoter. For studies of autophagy in vivo, GFP-LC3 C57BL/6J mice were crossed with beclin $1^{+/-} 129 \mathrm{~Sv} / \mathrm{J} \times \mathrm{C} 57 \mathrm{BL} / 6 \mathrm{~J}$ mice. (A more detailed analysis of the development of the GFPLC3 C57BL/6J mice for in vivo autophagy detection will be presented elsewhere; N. Mizushima and Y. 
a
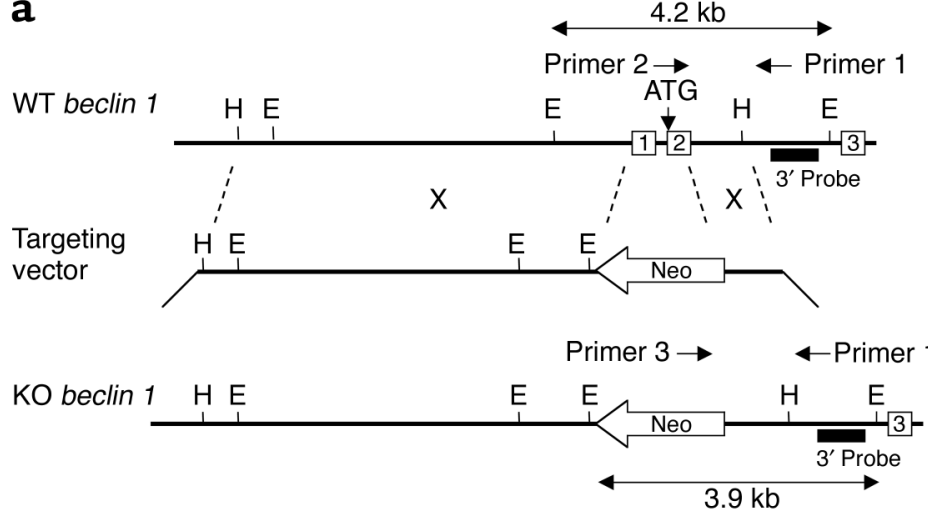

b

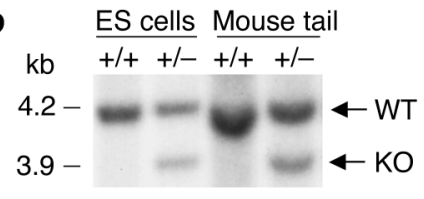

d

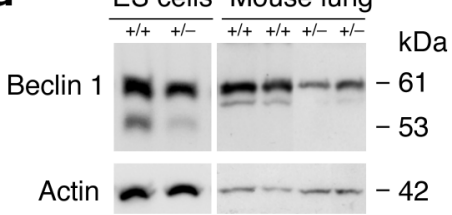

Figure 1

Targeted disruption of beclin 1 in mice. (a) Restriction maps of the wild-type beclin 1 allele (top), the beclin 1 targeting vector (middle), and the predicted targeted beclin 1 allele (bottom). Restriction sites are as follows: EcoRI (E), HindIII $(\mathrm{H})$. The targeting construct contains a cassette with the neomycin resistance gene (Neo) that has replaced exons 1 and 2 of the beclin 1 gene. "X" denotes regions of homologous recombination between the targeting vector and wildtype allele. The beclin 1 genomic fragment used as a 3' external probe for Southern blot analysis is indicated by a solid black box. Expected sizes of the EcoRI fragments that hybridize with the probe are indicated. (b) Southern blot analysis of genomic DNA from beclin $1^{+/+}$and beclin $1^{+/-}$ES cells and mouse tails. The DNA was digested with EcoRI and hybridized with the probe indicated in $\mathbf{a}$. The sizes of wild-type (WT) and disrupted (KO) alleles are shown. (c) PCR genotyping of genomic DNA from beclin $1^{+/-}$and beclin $1^{+/+}$ES cells and mouse tail DNA. Primers 1 and 2 in a were used to detect the wild-type allele, and primers 1 and 3 in a were used to detect the knockout allele. (d) Western blot analysis of Beclin 1 protein expression in beclin $1^{+/+}$and beclin $1^{+/}$- ES cells and mouse lung samples. Sizes of Beclin 1 isoforms and an actin control are indicated on the right. Lung lysates were prepared from 2-month-old mice. Similar results were observed for samples from six different mice of each genotype.
Ohsumi, unpublished data). For all analyses of cellular proliferation and autophagy in vivo, studies were performed using beclin $1^{+/+}$and beclin $1^{+/-}$mice that had been backcrossed to C57BL/6J for six generations.

All procedures involving animals and their care were approved by the Institutional Animal Care and Use Committee of Columbia University according to guidelines that are in compliance with the NIH's Guide for the Care and Use of Laboratory Animals.

Southern blot analysis, PCR genotyping, and mutation analysis. Genotyping of tail genomic DNA was performed to detect wild-type and beclin 1 knockout alleles by Southern blotting using EcoRI digestion and a 380-bp 3' external genomic probe, and by PCR amplification. The sense primer 5'-CTGGACACGAGTTTCAAGATCCTG-3' (primer 2 in Figure 1a) and the antisense primer $5^{\prime}$-GGGCATGGTAGCACACAGACCTC-3' (primer 1 in Figure 1a) were used to detect the wild-type beclin 1 allele (yielding a PCR product of $1,060 \mathrm{bp}$ ), and the sense primer $5^{\prime}$ TGCGGGCCAGAGGCCA CTTGTGTAGC-3’ (primer 3 in Figure 1a) and the identical antisense primer were used to detect the knockout beclin 1 allele (yielding a PCR product of $1,130 \mathrm{bp}$ ). The presence of the HBV largeenvelope gene was detected by PCR amplification of tail genomic DNA (sense primer, 5'-GAGTCTAGACTCGTGGTGGA-3'; antisense primer, 5'-CGAACCACTGAACAAA TGGC- $\left.3^{\prime}\right)$ and by serum ELISA to detect hepatitis B surface antigen (Auszyme Monoclonal Diagnostic kit; Abbott Laboratories, Abbott Park, Illinois, USA). Genomic DNA from tumors arising in beclin $1^{+/-}$mice and from corresponding normal tissue was subjected to Southern blot analysis as described above to detect wild- type and beclin 1 knockout alleles. Mutation analysis of the 12 exons and promoter region of beclin 1 was performed on tumor genomic DNA by sequencing PCR products generated using intronic primer sets provided in Supplementary Table 1 (http://www.jci.org/cgi/ content/full/112/12/1809/DC1).

Histologic analysis. For studies examining the effects of beclin 1 heterozygous deletion on spontaneous tumorigenesis, complete necropsies were performed on 104 beclin $1^{+/-}$mice and 95 beclin $1^{+/+}$littermates, including 67 beclin $1^{+/-}$and 49 beclin $1^{+/+}$mice aged $13-16$ months and 37 beclin $1^{+/-}$and 46 beclin $1^{+/+}$mice aged $16-18$ months. Mice were randomly sacrificed during this age interval without any preselection for adverse clinical status or the presence of palpable tumors. Tumors greater than $1 \mathrm{~mm}$ that were present on gross examination were recorded. H\&E-stained sections of all major organs were examined separately by two pathologists blinded to genotype (G. Bhagat and G. Cattoretti), and all malignant lesions noted on microscopic examination were recorded. Lymphoid lesions were classified using the Bethesda proposal for classification of lymphoid neoplasms in mice (34).

All neoplastic lesions were stained for Beclin 1 using the polyclonal rabbit anti-Beclin 1 antibody described by Kihara et al. (20) (provided by T. Yoshimori, National Institute of Genetics, Mishima, Japan). Routine immunohistochemistry protocols were used to detect thyroid transcription factor-1 (TTF-1) expression in lung carcinomas, and Pax5, B220, CD3, BCL-6, IRF4, and $\kappa$ light chains in lymphoproliferative lesions (35).

For studies examining the effect of beclin 1 heterozygous deletion on $\mathrm{HBV}$ carcinogenesis, livers were 
resected from 13-month-old offspring of HBV transgenic $\times$ beclin $1^{+/-}$crosses, including $27 \mathrm{HBV}^{+}$beclin $1^{+/-}$ mice, $32 \mathrm{HBV}^{+}$beclin $1^{+/+}$mice, $35 \mathrm{HBV}^{-}$beclin $1^{+/-}$mice, and $29 \mathrm{HBV}^{-}$beclin $1^{+/+}$mice. H\&E-stained liver sections were examined by a liver pathologist (G. Bhagat) blinded to genotype, and classified according to the extent of preneoplastic changes in a semiquantitative fashion.

Mammary glands from 6- to 9-month-old virgin beclin $1^{+/-}$and beclin $1^{+/+}$female littermates were examined by whole-mount preparations and H\&E staining of whole-mount sections as described previously (36). Mouse mammary gland proliferative lesions were classified according to the Annapolis guidelines (37). For quantitation of mammary epithelial cell proliferation experiments, 5 -week-old female virgin mice were injected with $100 \mu \mathrm{g} B r d U / g$ body weight 2 hours prior to sacrifice. BrdU incorporation was detected in mammary gland sections using a commercially available kit (Roche Diagnostics Corp., Indianapolis, Indiana, USA), and apoptosis was detected by TUNEL staining of adjacent sections using ApopTag Peroxidase In Situ Apoptosis Detection Kit (Intergen Co., Purchase, New York, USA) according to the manufacturer's instructions.

For studies of germinal center formation, 2-monthold female mice were immunized intraperitoneally with $5 \times 10^{6}$ sheep rbc's (Colorado Serum Co., Denver, Colorado, USA). Eight days after immunization, mice were sacrificed, and spleen sections were stained with the germinal center B lymphocyte marker peanut agglutinin (PNA; Sigma-Aldrich) (38) to identify germinal centers in immunohistochemical staining. For isolation of germinal B center lymphocytes for quantitative electron microscopy analysis, spleen cells were stained with the B220 B cell marker and PNA, and the B220-high, PNAhigh cell population was isolated by FACS sorting as described previously (39) using FACStarPLUS (Becton Dickinson and Co., Franklin Lakes, New Jersey, USA) equipped with two lasers (488 $\mathrm{nm}$ and $680 \mathrm{~nm}$ ).

Autophagy analysis. For analysis of autophagy by quantitation of punctate GFP-LC3 staining, 2-month-old male and female starved GFP-LC3 transgenic beclin $1^{+/+}$, GFP-LC3 transgenic beclin 1+/-, and GFP-LC3 negative control mice were perfused with $4 \%$ paraformaldehyde, and cryosections were prepared from selected organs. GFP fluorescence staining was visualized using an Inovision Deconvolution Microscope, and ten images per organ were recorded for five mice per genotype (using a $\times 100$ objective for muscle and a $\times 40$ objective for lung). The number of GFP-LC3 punctate regions per 1,000 $\mu \mathrm{m}^{2}$ of muscle and the number of GFP-LC3 punctate regions per linear millimeter of bronchial epithelium were quantitated by an observer blinded to genotype. For analysis of autophagy by quantitative electron microscopy, Epon-embedded cells prepared as described previously (40) were used to determine the number of autophagic vacuole profiles per square micrometer of cell area. Autophagic vacuole profiles were counted under the microscope using $\times 12,000$ magnification, and cell area was estimated by point counting (41) from negatives taken at $\times 400$ magnification by an observer blinded to genotype. The volume density of both early, immature autophagic vacuoles and late, degradative autophagic vacuoles was determined.

\section{Results}

Beclin 1 heterozygous disruption in mice results in increased spontaneous tumorigenesis. To evaluate the hypothesis that beclin 1 is a haplo-insufficient tumor-suppressor gene, we studied spontaneous tumorigenesis in mice with heterozygous deletion of beclin 1. First, we generated mice with a targeted disruption in the beclin 1 locus by homologous recombination. The targeting vector was designed to replace exons 1 and 2 of beclin 1 with the neomycin resistance gene (Figure 1a). ES cells and mice harboring the targeted allele were identified by Southern blotting and PCR analyses (Figure 1, b and c). Beclin 1 heterozygous mice were crossed against each other, and the viable offspring included 156 wild-type mice and 298 heterozygous-deficient mice, indicating embryonic lethality of homozygous-deficient mice. We confirmed that beclin 1 heterozygous disruption results in decreased Beclin 1 protein expression both in ES cells and in tissues of beclin 1 heterozygous-deficient (beclin $1^{+-}$) mice (Figure 1d).

Next, we sacrificed approximately 100 beclin $1^{+/-}$and 100 beclin $1^{+/+}$control littermates aged $13-18$ months (Figure 2) and examined all major organs macroscopically and microscopically. Beclin $1^{+/-}$mice had a significantly higher probability of having a malignancy detected upon gross examination $(P<0.0001$, log-rank test; Figure 2a); approximately $15 \%$ of beclin $1^{+-}$mice had palpable tumors visible at the time of autopsy that were histologically confirmed to represent malignancies, as compared with only $1 \%$ of beclin $1^{+/+}$littermates $(P<0.0001$, Fisher's exact test; Figure $2 c)$. Upon microscopic examination, beclin $1^{+/-}$mice also had a significantly higher probability than beclin $1^{+/+}$mice of harboring a malignancy $(P<0.0001$, log-rank test $)$, although more microscopic tumors were observed at an increased frequency with advancing age in mice of both genotypes (Figure $2 \mathrm{~b}$ ). In total, approximately $30 \%$ of beclin $1^{+/-}$as compared with $14 \%$ of beclin $1^{+/+}$mice had malignancies ( $P<0.0001$, Fisher's exact test; Figure $2 \mathrm{~d}$ ), indicating that beclin 1 heterozygous disruption significantly increases the chance of developing a spontaneous malignancy in mice. In addition to this large cohort of mice that we sacrificed between 13 and 18 months of age, we also observed some tumor-associated mortality in 6- to 13 -month-old beclin $1^{+/-}$mice, but not in control beclin $1^{+/+}$littermates (data not shown).

Three types of malignancies were noted in the beclin $1^{+-}$ mice: lung cancers, liver cancers, and lymphomas. Beclin $1^{+/-}$mice developed a greater number of lung carcinomas (Figure 2e) than beclin $1^{+/+}$mice, and the lung carcinomas tended to be significantly larger, with $80 \%$ visible as macroscopic subpleural nodules, whereas the few lung carcinomas observed in the beclin $1^{+/+}$mice were only detectable microscopically. The lung cancers showed features of well-differentiated human papillary adenocarci- 
a
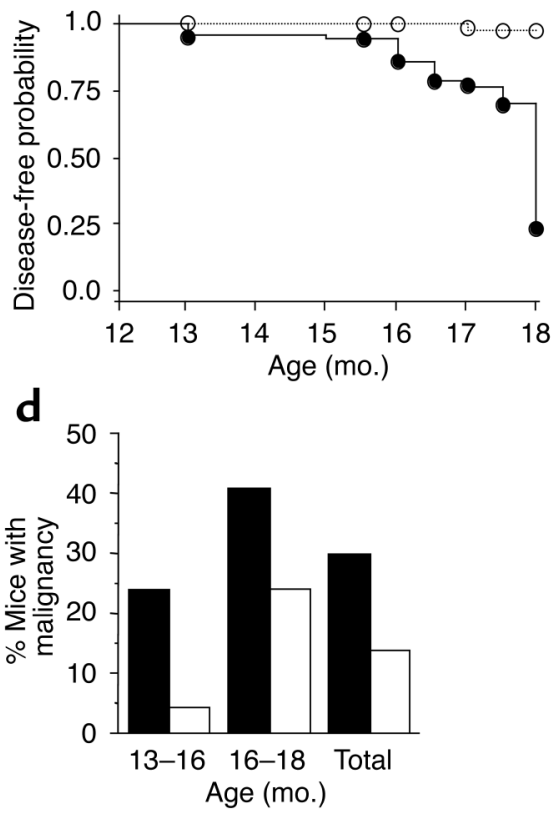

b

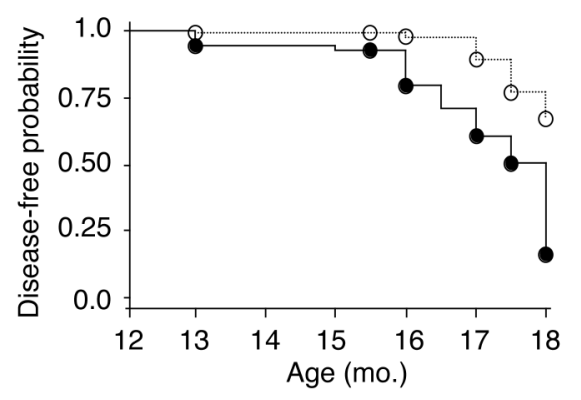

e

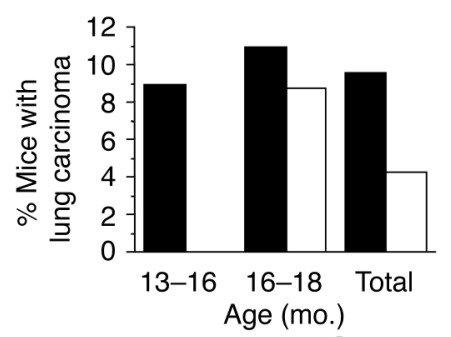

c

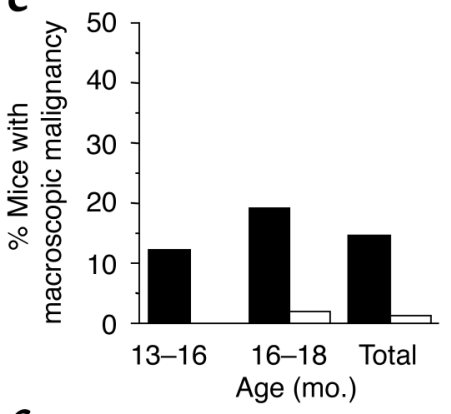

f

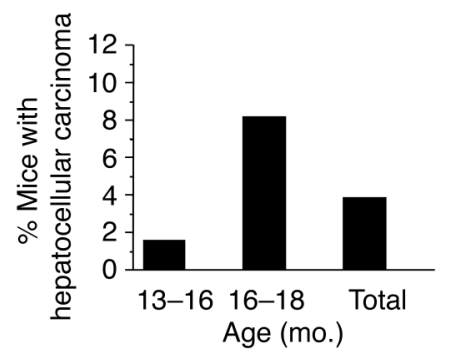

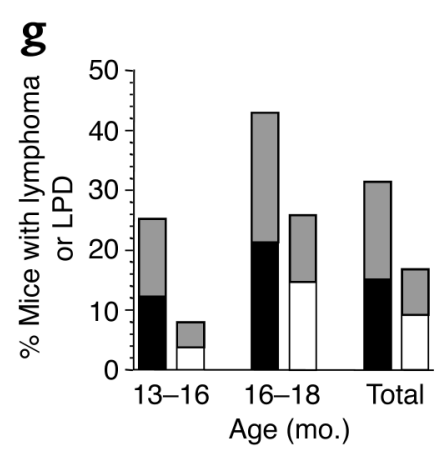

h

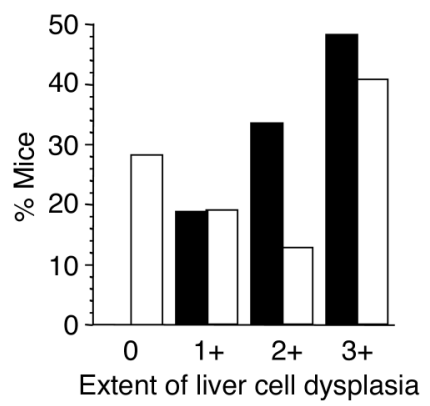

Figure 2

Increase in the frequency of spontaneous malignancies (a-g) and accelerated development of HBV-induced premalignant lesions in beclin 1 heterozygous-deficient mice (h). (a and b) Kaplan-Meier plot of time to development of macroscopic malignancy (a) and any malignancy (b) in beclin $1^{+/-}$(solid lines, filled circles) versus beclin $1^{+/+}$(dotted lines, open circles) mice $(P<0.0001$, log-rank test). "Macroscopic malignancy" refers to tumors observed upon gross inspection that were subsequently confirmed to be malignancies upon histologic examination. "Any malignancy" denotes either a macroscopic or a microscopic malignancy detected upon complete histologic survey of all major internal organs. (c-g) Prevalence of macroscopic malignancies (c), all malignancies (d), lung carcinomas (e), hepatocellular carcinomas (f), and lymphomas and lymphoproliferative disease (LPD; $\mathbf{g}$ ) in beclin $1^{+/-}$(black bars) versus beclin $1^{+/+}$(white bars) mice $(P<0.0001$, Fisher's exact test for $\mathbf{c}-\mathbf{g}$ ). In $\mathbf{g}$, black denotes lymphoma and gray denotes lymphoproliferative disease. (h) Extent of small-cell dysplasia in livers from 13-month-old beclin $1^{+/-}(n=27$; black bars $)$ versus beclin $1^{+/+}(n=32$; white bars $)$ HBV transgenic mice. The scale for small-cell dysplasia (72) is: 0 , absent or rare foci; $1+,<25 \%$ of liver with small-cell dysplasia; $2+, 25-50 \%$ of liver with small-cell dysplasia; $3+,>50 \%$ of liver with small-cell dysplasia. Beclin $1^{+/-}$HBV transgenic mice have significantly more severe disease $\left(P=0.0289\right.$, Mantel-Haenszel $\chi^{2}$ test $)$.

nomas, including a bronchioalveolar growth pattern with papillary architecture, nuclear enlargement, prominent nucleoli, increased mitotic rate (Figure 3a), and nuclear immunoreactivity for TTF-1, a tissue-specific transcription factor expressed in bronchial and type II alveolar epithelial cells (42) (Figure 3c). In addition, all lung carcinomas had detectable Beclin 1 protein expression in the tumor cells (Figure $3 \mathrm{~b}$ ). beclin $1^{+/-}$mice also had an increased frequency of lung lesions in earlier stages of neoplasia, including hyperplastic alveolar epithelium resembling human atypical adenomatous hyperplasia, a proposed precursor dysplastic lesion that leads to invasive lung carcinoma (43), and bronchioalveolar adeno- mas composed of monomorphous cells with minimal cytologic atypia (data not shown). Well-differentiated hepatocellular carcinomas (mostly trabecular, often with large foci of necrosis) were observed exclusively in the beclin $1^{+/-}$mice (Figures $2 \mathrm{f}$ and $3 \mathrm{~d}$ ), and these tumors also exhibited Beclin 1 immunoreactivity (Figure 3e).

Both beclin $1^{+/-}$and beclin $1^{+/+}$control littermates developed lymphomas, but the lymphomas occurred more frequently, at an earlier age, and were more likely to present as palpable masses (versus only as a microscopic finding) in the beclin $1^{+/-}$mice (Figure $2 \mathrm{~g}$ ). The observed lymphomas were distributed into five morphologic types according to the Bethesda proposal for 

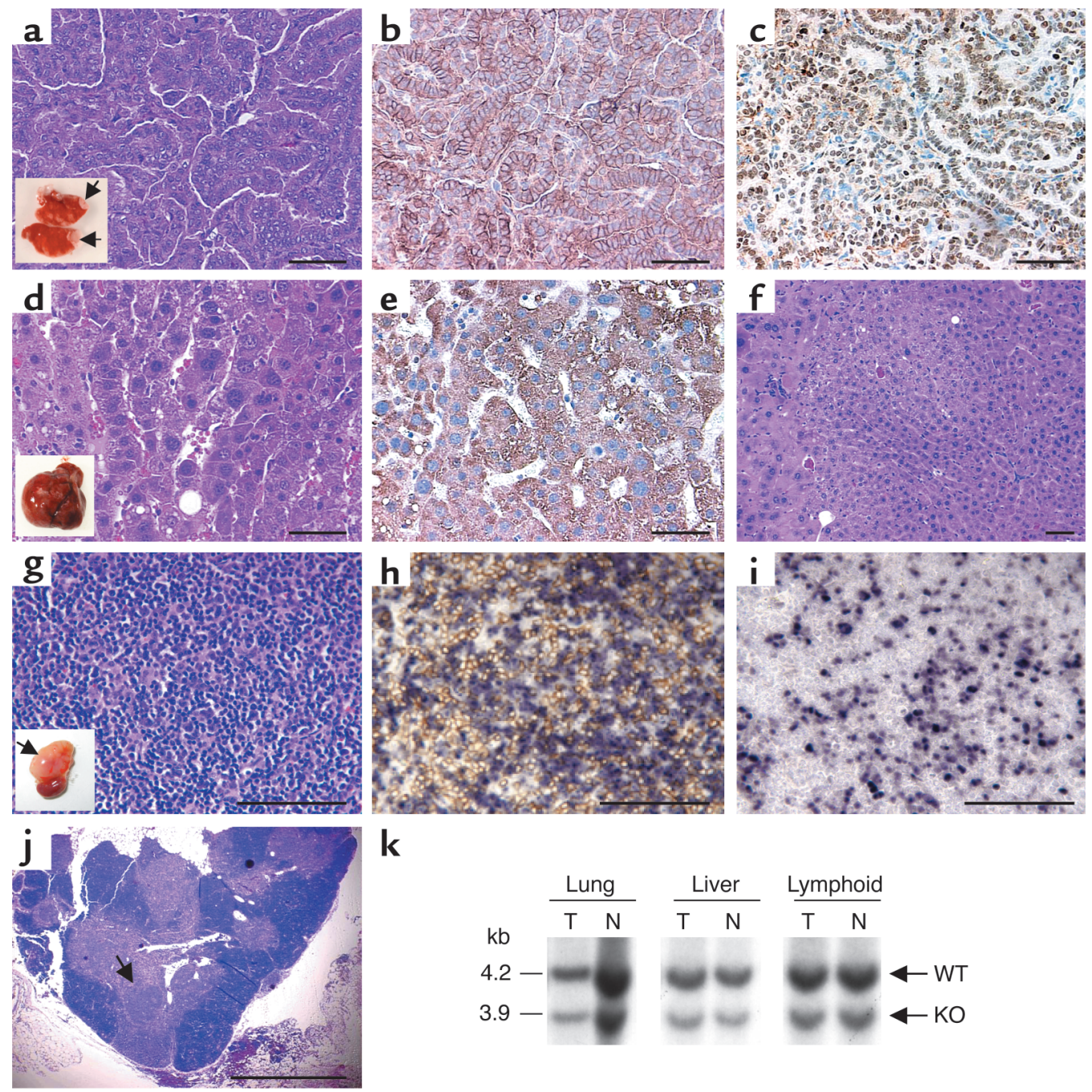

k

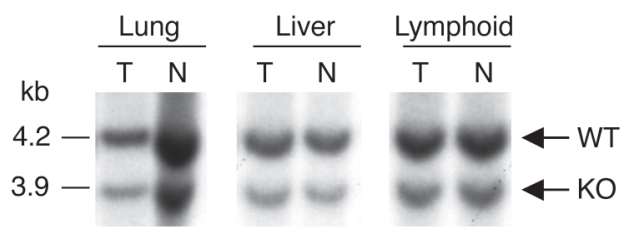

Figure 3

Histopathologic and molecular characterization of lesions in beclin $1^{+/-}$mice. (a-c) Representative well-differentiated papillary lung carcinoma in a beclin $1^{+/-}$mouse, stained with H\&E (a), anti-Beclin 1 (b), or anti-TTF-1 (c). The inset in a shows lungs with subpleural tumor nodules (arrows). Beclin 1 immunoreactivity levels similar to those shown in $\mathbf{b}$ were observed in all lung carcinomas in beclin $1^{+/-}$mice $(n=10$; data not shown). (d and e) Representative well-differentiated hepatocellular carcinoma in a beclin $1^{+/-}$mouse, stained with H\&E (d) or anti-Beclin 1 (e). The inset in $\mathbf{d}$ shows gross pathology of liver tumor. Beclin 1 immunoreactivity levels similar to those shown in e were observed in all hepatocellular carcinomas identified in beclin $1^{+/-}$mice $(n=4$; data not shown). (f) Representative area of preneoplastic small-cell dysplasia in the liver of a beclin $1^{+/-}$mouse that transgenically expresses the HBV large-envelope polypeptide. (g-i) Representative DLCL in a beclin $1^{+/-}$mouse, stained with H\&E (g), anti-Pax5 (dark purple) and anti-CD3 (brown; h), and anti-BCL-6 (i). The inset in g shows lymphoma (arrow) adjacent to normal kidney. (j) Example of lymphoproliferative disease in the thymus of a beclin $1^{+/-}$mouse with medullary follicular hyperplasia and cortical effacement. The arrow denotes a germinal center. (k) Southern blot analysis to detect the wild-type and disrupted beclin 1 allele in tumor samples and matched normal tissue. No evidence of allelic loss is seen in beclin $1^{+/-}$tumors. Data are shown for one example of each of the three types of malignancy observed. Similar findings were observed for all palpable malignancies $(n=15)$. Scale bars: $\mathbf{a}-\mathbf{i}, 50 \mu \mathrm{m} ; \mathbf{j}, 1 \mathrm{~mm}$.

classification of lymphoid neoplasms in mice (34), including diffuse large-cell lymphoma (DLCL), follicular lymphoma, the immunoblastic variant of DLCL (DLCL-IB), anaplastic plasmacytoma, and histiocytic sarcoma (see Figure 3, g-i, for representative images of DLCL in a beclin $1^{+/-}$mouse). Both beclin $1^{+/-}$and beclin $1^{+/+}$ mice had DLCLs and follicular lymphomas, whereas DLCL-IBs $(n=3)$ and histocytic sarcomas $(n=2)$ were observed only in beclin $1^{+/-}$mice and anaplastic plasmacytoma was observed in one beclin $1^{+/+}$mouse. DLCLs were the most common type of observed lymphomas, and most of these were immunoreactive for BCL-6, a transcriptional repressor protein that controls germinal center formation and is implicated in the pathogenesis of human B cell lymphomas (reviewed in ref. 44) (Figure 3i). Using a PCR clonality assay (45), we confirmed clonal Ig gene rearrangements in two representative BCL-6-positive DLCLs from beclin $1^{+/-}$mice, and, using a PCR assay for analysis of Ig gene hypermutation (46), we confirmed that the $V$ genes in the BCL-6-positive DLCLs had somatic hypermutation, consistent with a germinal center or post-germinal 
center phenotype (data not shown). In addition to frank lymphomas, we also noted that beclin $1^{+/-}$mice had an increased frequency of extranodal, splenic, and nodal lymphoproliferative disease (Figures $2 \mathrm{~g}$ and $3 \mathrm{j}$ ). Malignancies in beclin $1^{+/-}$mice do not contain mutations in the wild-type beclin 1 allele. The increased frequency of spontaneous malignancies in multiple different organs in beclin $1^{+-}$mice suggested that beclin 1 is a haploinsufficient tumor-suppressor gene. To confirm this, we performed Southern blot and mutational analyses of genomic DNA from all macroscopic malignancies present in the beclin $1^{+/-}$mice $(n=15)$. Southern blot analysis did not reveal any deletions or rearrangements of the remaining wild-type beclin 1 allele (Figure 3k). Similarly, we sequenced all 12 beclin 1 exons and the beclin 1 promoter region in genomic DNA from these malignancies and did not observe any mutations in the wild-type beclin 1 allele. In addition, as noted above, Beclin 1 protein was detected by immunohistochemistry in all lung carcinomas and all hepatocellular carcinomas in the beclin $1^{+/-}$mice (Figure $3, \mathrm{~b}$ and e). Furthermore, Beclin 1 protein expression was detected by Western blot analysis in the lymphomas in beclin $1^{+/-}$ mice (data not shown). Thus, we could find no evidence for beclin 1 mutation or silencing of Beclin 1 protein expression in the tumors observed in beclin $1^{+/-}$mice. Together, these data demonstrate that functional inactivation of one beclin 1 allele is sufficient to promote tumorigenesis and that beclin 1 is a haplo-insufficient tumor-suppressor gene.

Beclin 1 heterozygous disruption in mice accelerates the development of HBV-induced premalignant lesions. To examine whether beclin 1 heterozygous deletion also accelerates the neoplastic process in an established mouse tumor model, we crossed beclin $1^{+/-}$and beclin $1^{+/+}$ mice with mice that transgenically express the HBV large-envelope polypeptide under the transcriptional control of the mouse albumin promoter (herein referred to as HBV transgenics) (33). The livers of HBV transgenic mice progress through a series of hyperplastic and preneoplastic stages that culminate in frank hepatocellular carcinoma (33). We chose this model because the liver is a major site of nutrient starvation-induced autophagy (reviewed in ref. 47); because decreased autophagic activity has been postulated to play a role in chemical-induced hepatocellular carcinogenesis in rats (14); and because protein caloric restriction, a trigger of autophagy, represses HBVinduced liver injury in HBV transgenic mice (48).

To detect differences in the progression of HBVinduced liver cell neoplasia, we sacrificed beclin $1^{+/-}$and beclin $1^{+/+} \mathrm{HBV}$ transgenic mice at a time point prior to the predicted onset of hepatocellular carcinoma (33). At 13 months of age, we found that the severity of preneoplastic changes, characterized by the extent of liver with small-cell dysplasia - an important histopathologic predictor of malignant transformation (49-51) was significantly increased in the beclin $1^{+/-}$compared with the beclin $1^{+++}$mice $\left(P=0.0289\right.$, Mantel-Haenszel $\chi^{2}$ test; Figures $2 \mathrm{~h}$ and 3f) (No small-cell dysplastic changes were observed in the livers of $\mathrm{HBV}^{-}$littermates that were either beclin $1^{+/-}$or beclin $1^{+/+}$). Thus, beclin 1 heterozygous deletion both increases susceptibility to spontaneous malignancies and accelerates HBVinduced hepatocellular carcinogenesis.

Beclin 1 heterozygous disruption results in increased cellular proliferation in vivo. These findings raised the question of whether beclin 1 heterozygous deletion affects cell growth control in vivo. Although mammary tumors were not observed in our large cohort of 13- to 18month-old mice, we found proliferative lesions present in mammary gland whole-mount examinations from 10 of 15 beclin $1^{+/-}$compared with 0 of 15 beclin $1^{+/+} 6$ - to 9-month-old mice. Histologically, these lesions included mammary intraepithelial neoplasia (also known as ductal carcinoma in situ), adenomyoepithelioma, and acinar neoplasia (Figure 4, a-d). These observations, coupled with the frequent monoallelic deletions of beclin 1 in human breast cancer (29), suggested that mammary epithelial cell growth control may be altered by beclin 1 heterozygous disruption.

To evaluate this, we quantitated epithelial cell proliferation (using BrdU incorporation staining) and apoptosis (using TUNEL staining) in developing mammary glands from 5-week-old female mice. No differences were detected in the percentage of TUNELpositive cells in terminal end buds (TEBs) and ducts in beclin $1^{+/-}$versus beclin $1^{+/+}$mice (data not shown), indicating that beclin 1 heterozygous deletion does not alter mammary epithelial cell apoptosis. However, we observed significant differences both in the distribution of cellular proliferation in the TEBs and in the quantity of cellular proliferation in the TEBs and ductal epithelial cells. In the TEBs from mammary glands of wild-type littermates, a normal pattern of cellular proliferation was observed and the majority of cells undergoing DNA synthesis were localized in the cap cell and body region (Figure 4f). In contrast, in the mammary glands of beclin $1^{+/-}$mice, there was a marked increase in BrdU staining in the neck region (Figure 4e) and a significant increase in the overall percentage of BrdU-positive cells in the TEBs $(P=0.025$; Figure $4 \mathrm{~g}$ ), indicating that beclin 1 heterozygous deficiency results in abnormal cellular proliferation in the TEBs. In addition, the mammary ducts of beclin $1^{+/-}$ mice showed a marked increase in DNA synthesis, with more than $35 \%$ of cells labeling positive with BrdU as compared with approximately $5 \%$ in the beclin $1^{+/+}$mice $(P<0.0001$; Figure 4j). Consistent with the hyperproliferation of the mammary ductal epithelial cells, the mammary ducts in the beclin $1^{+/-}$mice frequently were morphologically abnormal (Figure 4h), with multiple layers of epithelial cells (versus single layers in the wild-type mice; Figure 4i) and intraluminal collections of epithelial cells.

We further confirmed the pro-proliferative effect of beclin 1 heterozygous disruption in a cell type that gave rise to increased spontaneous malignancies in the 

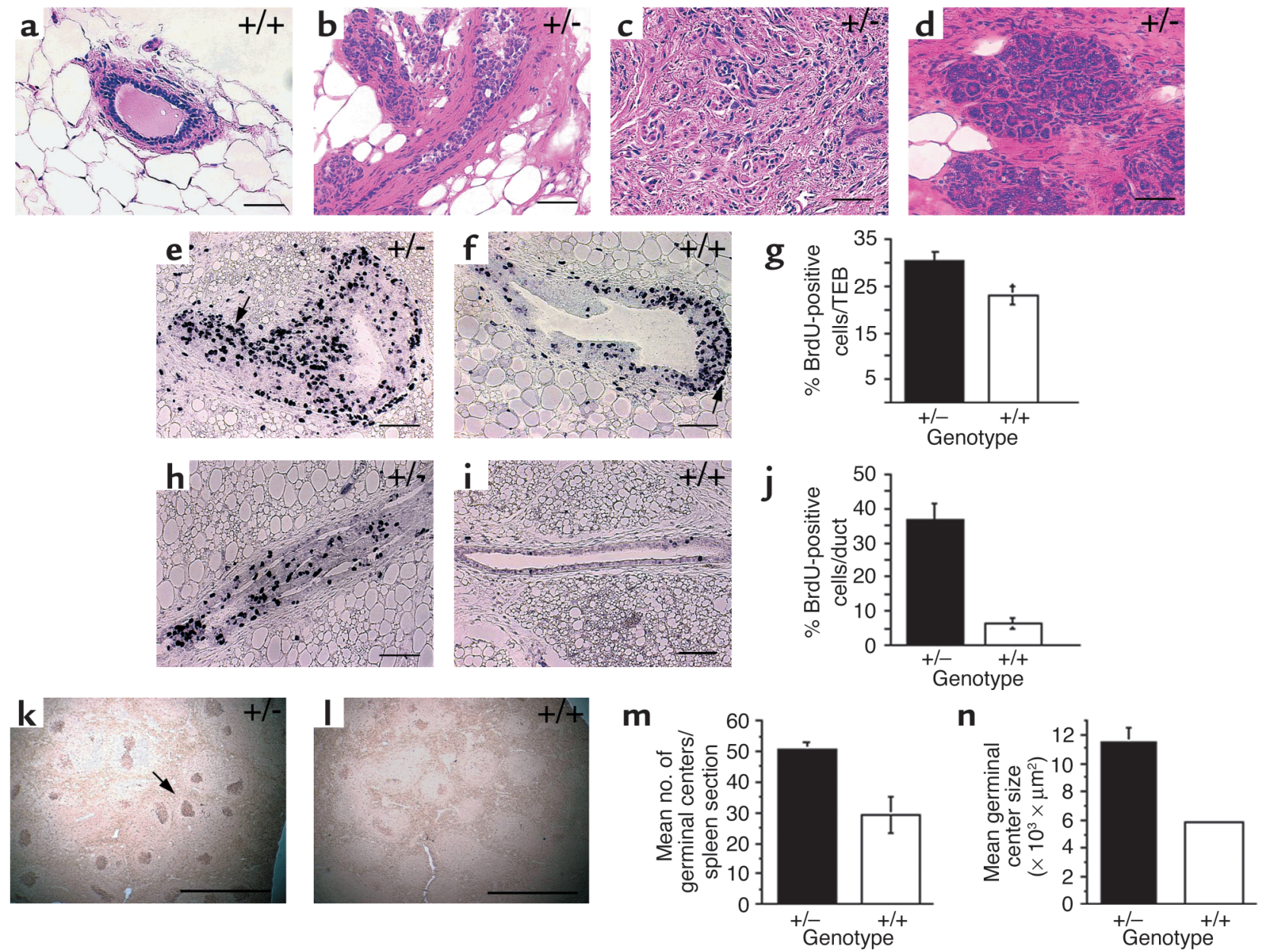

\section{Figure 4}

Beclin 1 heterozygous deletion alters cell-growth control in the mammary gland and in splenic germinal centers. (a-d) H\&E sections of normal mammary epithelial duct in a beclin $1^{+/+}$mouse (a) and hyperplastic/neoplastic lesions in the mammary glands of beclin $1^{+/-} 6$ - to 9 -month-old virgin mice (b-d), including mammary intraepithelial neoplasia (b), adenomyoepithelioma (c), and acinar neoplasia (d). (e-j) Representative images of BrdU staining of terminal end buds (TEBs) (e and $\mathbf{f}$ ) and mammary ducts ( $\mathbf{h}$ and $\mathbf{i})$ in 5 -week-old virgin mice and quantitation of percentage of BrdU-positive cells in TEBs $(\mathbf{g})$ and mammary ducts $(\mathbf{j})$. Results shown represent the mean \pm SEM of 15 TEBs $(\mathbf{g})$ or 15 ducts (j) from five mice (aged 5 weeks) per genotype. Significant differences were observed between beclin $1^{+/-}$and beclin $1^{+/+}$genotypes for percentages of both BrdU-positive TEB cells $(P=0.025, t$ test $)$ and BrdU-positive ductal cells $(P<0.0001, t$ test $)$. The arrow in e indicates the neck region, and the arrow in $\mathbf{f}$ indicates the cap cell region. (k-n) Representative images of splenic germinal centers (arrow) labeled by PNA staining (38) 8 days after immunization with sheep rbc's ( $\mathbf{k}$ and $\mathbf{I})$, and quantitation of the number $(\mathbf{m})$ and size (n) of germinal centers. Results shown represent the mean \pm SEM from spleen sections analyzed from five mice per genotype. Significant differences were observed between beclin $1^{+/-}$and beclin $1^{+/+}$genotypes for both number $(P=0.027, t$ test $)$ and size $(P=0.018, t$ test $)$ of germinal centers. Scale bars: $\mathbf{a}-\mathbf{f}, \mathbf{h}$, and $\mathbf{i}, 100 \mu \mathrm{m} ; \mathbf{k}$ and $\mathbf{I}, 1 \mathrm{~mm}$.

beclin $1^{+/-}$mice, the germinal center splenic B cell. Following immunization of 2-month-old mice with sheep rbc's, we found a significant increase in both the number $(P=0.027, t$ test $)$ and the size $(P=0.018, t$ test $)$ of germinal centers in the spleens of beclin $1^{+/-}$as compared with beclin $1^{+/+}$mice (Figure $4, \mathrm{k}-\mathrm{n}$ ). Together with the results in mammary epithelial cells, these results indicate that beclin 1 heterozygous disruption increases cellular proliferation in vivo, beginning at an early age. We speculate that the increased cellular proliferation in beclin $1^{+/-}$mice may increase the number of genetic mutations that occur over the lifetime of the animals, thereby contributing to the increased spontaneous tumorigenesis that occurs in older beclin $1^{+/-}$mice.
Beclin 1 heterozygous disruption decreases autophagy in vivo. As noted above, previous studies have indicated that mammalian Beclin 1, like its yeast (18) and Caenorbabditis elegans (52) orthologs, plays a role in cellular autophagy $(19,30)$. The yeast homolog Apg6/Vps30p is also involved in vacuolar protein sorting $(53,54)$, raising the possibility that mammalian Beclin 1, as part of a PI3K complex that may localize in the trans-Golgi network (20), is involved in other membrane-trafficking pathways. However, such other functions have not yet been identified in mammalian cells, and human beclin 1 and its orthologs in C. elegans and Arabidopsis thaliana rescue only autophagy, but not vacuolar protein sorting function in apg6/vps30-null yeast 


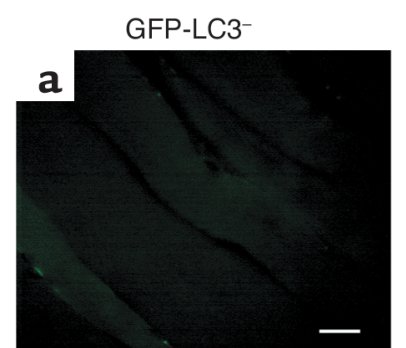

GFP-LC3-
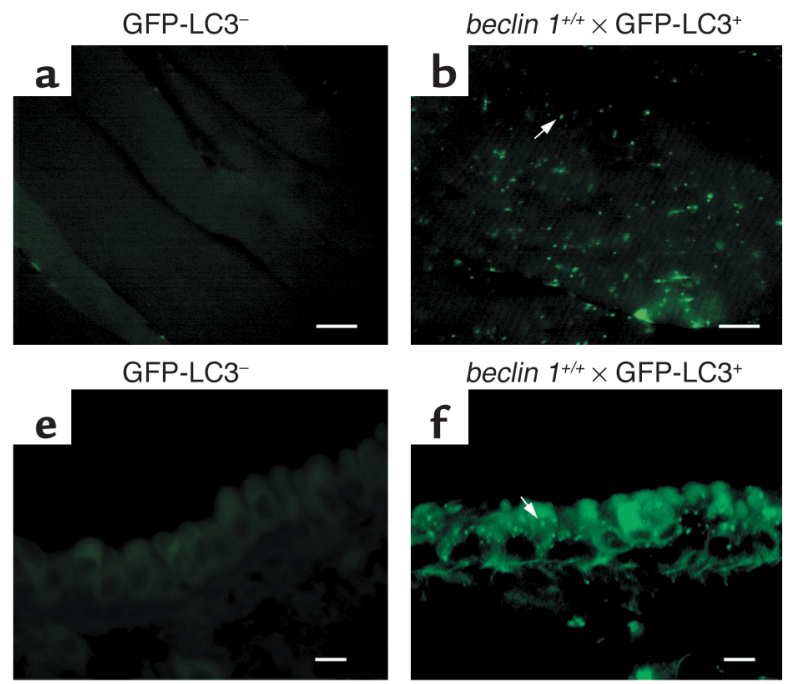

beclin $1^{+/+} \times$GFP-LC3 ${ }^{+}$

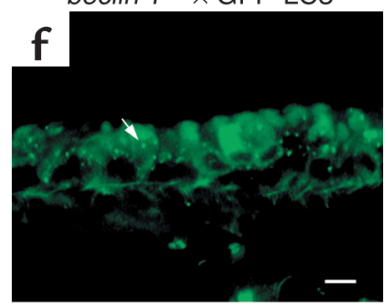

i

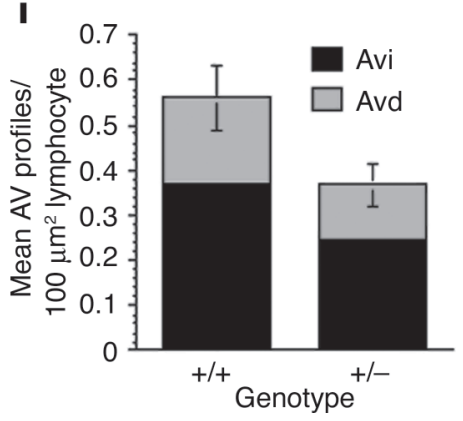

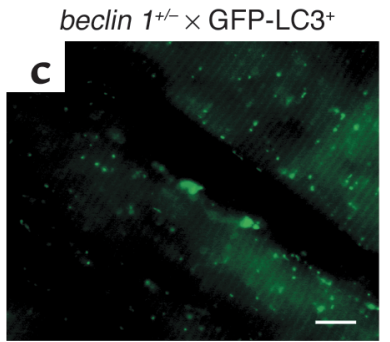

beclin $1^{+-} \times$GFP-LC3 ${ }^{+}$

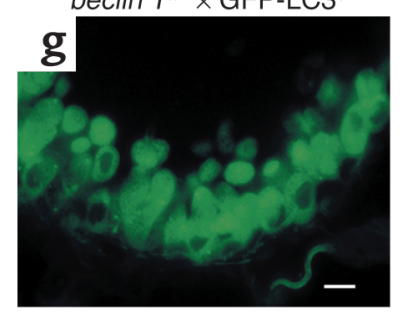

$\mathrm{h}$

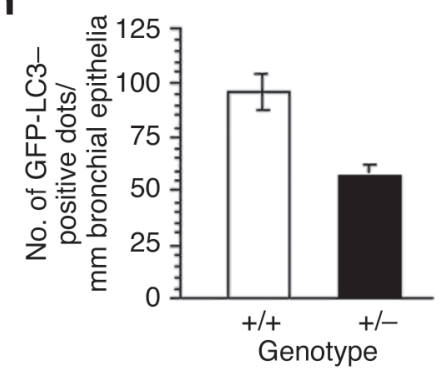

Figure 5

Beclin 1 heterozygous deletion decreases autophagy in muscle (a-d), bronchial epithelia (e-h), and germinal center B lymphocytes (i). (a-d) Representative images of GFP-LC3 staining in ( $\mathbf{a}-\mathbf{c})$ and quantitation of GFP-LC3-positive dots (d) in muscle from 2-month-old mice subjected to 24-hour starvation. The $x$ axis labels denote beclin 1 genotype. Results shown in d represent the mean \pm SEM for approximately 50 images obtained from five mice per genotype $(P<0.0001, t$ test). (e-h) Representative images of GFP-LC3 staining (e-g) and quantitation of GFP-LC3-positive dots (h) in bronchial epithelial tissue from 2-month-old mice subjected to 24-hour starvation. The $x$ axis labels denote beclin 1 genotype. Results shown in h represent the mean \pm SEM for approximately 50 images obtained from five mice per genotype $(P<0.0001, t$ test). (i) Morphometric electron microscopic quantitation of autophagic vacuole (AV) profiles in germinal center B lymphocytes isolated from 2-month-old nonstarved mice. The $x$ axis labels denote beclin 1 genotype. Avi denotes early, immature autophagic vacuoles, and Avd denotes late, degradative autophagic vacuoles. Results shown in i represent the mean \pm SEM for parallel quantitations from seven to eight grid squares $(P=0.02, t$ test $)$. Arrows in $\mathbf{b}$ and $\mathbf{f}$ denote representative GFP-LC3-positive punctate dots that are quantitated in $\mathbf{d}$ and $\mathbf{h}$, respectively. Scale bars: $10 \mathrm{~nm}$.

(refs. 19, 52; and B. Levine et al., unpublished data). Therefore, we focused on determining whether heterozygous deletion of beclin 1 in mice affects its known function in autophagy.

To accomplish this, we measured autophagy in tissues from beclin $1^{+/-}$and beclin $1^{+/+}$mice that transgenically express an autophagy marker, GFP-LC3 (N. Mizushima and Y. Ohsumi, unpublished data). In the absence of autophagy, LC3 and its yeast homolog Apg8/Aut7p have a diffuse cytoplasmic distribution. Upon stimulation of autophagy, LC3 and Apg8/Aut7p localize to pre-autophagosomal and autophagosomal membranes (55-57). Previous studies have demonstrated that the visualization of GFP-positive punctate regions is a useful marker of autophagy in mammalian cells expressing GFP-LC3 (57) and in yeast cells expressing GFP-Apg8/Aut7p $(58,59)$. In GFP-LC3 transgenic mice, a punctate appearance of GFP staining also cor- responds to pre-autophagosomal or autophagosomal structures identified at the ultrastructural level, and the muscle has been shown to be an important site of starvation-induced autophagy (N. Mizushima and Y. Ohsumi, unpublished data).

First, we quantitated the amount of autophagy in starved muscle from 2-month-old beclin $1^{+/+}$and beclin $1^{+/-}$ GFP-LC3 transgenic mice. We found that the number of GFP-LC3-positive dots was significantly decreased in the muscle of starved beclin $1^{+/-}$as compared with beclin $1^{+/+}$ mice $(P<0.0001, t$ test), indicating that beclin 1 heterozygous deletion decreases autophagy during starvation conditions in muscle (Figure 5, a-d). Next, we asked whether beclin 1 heterozygous deletion affects autophagy in any of the tissues associated with increased spontaneous tumorigenesis. We found that the GFP-LC3 transgene was not expressed in lymphocytes, variably expressed in the liver, and strongly expressed in both 
type II alveolar and bronchial epithelial cells in the lung. Since the well-differentiated papillary lung carcinomas observed in the beclin $1^{+/-}$mice in our study displayed morphologic features strongly suggestive of a bronchial cell origin, we quantitated autophagy in starved bronchial epithelial cells from 2-month-old mice. While the absolute amount of autophagy was significantly less in bronchial epithelial cells than in muscle, autophagy was significantly reduced in bronchial epithelial cells from beclin $1^{+/-}$as compared with beclin $1^{+/+}$ mice $(P<0.0001, t$ test) by a magnitude similar to that observed in muscle (Figure 5, e-h).

To further evaluate whether autophagy is reduced in young beclin $1^{+/}$mice in cell types associated with increased spontaneous tumorigenesis in older mice, we performed quantitative electron microscopic morphometric analysis of autophagic vacuole accumulation in germinal center B lymphocytes (i.e., $\mathrm{B}^{2} 20^{+}, \mathrm{PNA}^{+}$) isolated from beclin $1^{+/-}$and beclin $1^{+/-}$mice 10 days after immunization with sheep rbc's. Our results indicate that beclin $1^{+/-}$germinal center $B$ lymphocytes have significantly fewer autophagic vacuoles than beclin $1^{+/}$germinal center B lymphocytes $(P=0.02, t$ test; Figure $5 \mathrm{i})$. Together, these findings demonstrate that beclin 1 heterozygous deletion reduces autophagic activity in a tissue that undergoes starvation-induced increases in autophagy (i.e., muscle) and in at least two cell types that are associated with increased spontaneous tumorigenesis in older mice (i.e., bronchial epithelial cells and germinal center B lymphocytes).

\section{Discussion}

Our observations provide direct genetic evidence that beclin 1, a gene that is monoallelically deleted in a high percentage of human breast, ovarian, and prostate cancers, is a haplo-insufficient tumor-suppressor and autophagy gene. To date, a number of different tumorsuppressor genes have been identified that function in different cellular process thought to be important in tumor suppression, including cell cycle regulation, DNA damage response, apoptosis regulation, and preservation of genomic stability (60). Our findings suggest that autophagy genes may represent a novel class of tumor-suppressor genes and that genetic disruption of autophagy may represent a novel mechanism of tumorigenesis.

While beclin 1 is the first downstream autophagy-execution gene linked to human cancer, it is important to note that certain oncogenes (e.g., PI3K and AKT) are already known to function in the negative regulation of autophagy $(61,62)$, and that the PTEN tumor-suppressor gene is known to function in the positive regulation of autophagy (62). Furthermore, rapamycin analogs that inhibit mTOR, a downstream target of class I PI3K and Akt, induce autophagy in yeast and mammalian cells (63); reduce neoplasia in tumors that arise in PTEN-deficient mice (64); and have yielded encouraging results in early clinical cancer trials $(65,66)$. It has been commonly assumed that the mechanisms by which the class I PI3K signaling pathway promotes oncogenesis involve the induction of cell growth in response to mitogenic signals, the inhibition of apoptosis, or the promotion of angiogenesis. Likewise, it is generally believed that the PTEN tumor-suppressor gene and the rapamycin analogs exert their antitumor effects by antagonizing these effects of class I PI3K signaling. However, based on our finding that genetic inactivation of beclin 1 (an autophagy gene known to be downstream of TOR in yeast; ref. 6) is sufficient to promote tumorigenesis, we propose that the downregulation of autophagy - by activating mutations in class I PI3K or AKT or inactivating mutations in PTEN - may contribute to oncogenesis.

Although the role of autophagy regulation by the class I PI3K signaling pathway in oncogenesis has not yet been established, recent data in C. elegans suggest that beclin 1 and other autophagy genes are necessary for a dauer developmental-arrest phenotype that is negatively regulated by the C. elegans class I PI3K signaling pathway and positively regulated by the C. elegans PTEN ortholog daf-18 (52). Such findings raise the strong possibility that autophagy genes play an evolutionarily conserved role in growth-arrest phenotypes that are negatively regulated by the oncogenic class I PI3K signaling pathway and positively regulated by the PTEN tumor suppressor. This possibility has important implications for the role of autophagy as a downstream cellular pathway that contributes to tumor suppression.

The precise mechanisms by which the autophagy function of Beclin 1 contributes to tumor suppression are not known. In the late 1970s, several studies demonstrated that the rate of cell growth represents a balance between the amount of protein synthesized and the amount of autophagic protein degradation and established autophagy as a lysosomal pathway involved in cell-growth control $(10,67-70)$. Autophagy may also contribute to tumor suppression by degrading specific cellular organelles and long-lived proteins that are essential for regulating cell growth, thereby functioning as a brake on cell growth in response to mitogenic signals. In this manner, decreased autophagy would be predicted to result in increased cellular proliferation which is what we observed in the mammary glands and germinal center B cells in younger mice in our study and, consequently, to increase the likelihood of the accumulation of secondary oncogenic mutations. Alternatively, by removing damaged organelles that increase genotoxic stress, autophagy may serve a more direct role in protecting cells against genetic mutations. The transformation potential of mutations in other oncogenes or tumor-suppressor genes may also be enhanced by decreased cellular autophagy; in support of this concept, we have previously shown that the tumorigenicity of MCF7 human breast carcinoma cells can be inhibited when autophagic activity is restored by beclin 1 gene transfer $(19,30)$. This ability of beclin 1 gene transfer to inhibit tumorigenicity of breast carcinoma cells suggests that beclin 1 functions as a tumor suppressor in a cell-autonomous fashion; it therefore seems unlikely 
that the increased spontaneous tumorigenesis observed in beclin 1 heterozygous-deficient mice can be explained by possible effects of reduced Beclin 1 expression on immune surveillance. Although autophagy has been described as a form of nonapoptotic cell death (reviewed in ref. 31), we did not observe a decrease in cell death in tissues of the beclin $1^{+/-}$mice (Figure 4 and data not shown), and it seems unlikely that decreased cell death contributes to the increased tumorigenesis in mice with heterozygous disruption of beclin 1 . However, we cannot rule out the possibility that as-yet undefined functions of mammalian Beclin 1 in vesicular transport (as part of a class III PI3K complex) contribute to its role in regulating cellular proliferation and tumorigenesis. Further studies in other autophagy-gene mouse knockout models will be important to confirm the role of the cellular autophagic machinery in tumor suppression.

In summary, our findings demonstrate that beclin 1 is a haplo-insufficient tumor-suppressor gene and raise the possibility that the genetic disruption of autophagy - either by mutation of downstream autophagy-execution genes or by mutations in upstream autophagyregulatory signaling pathways - may be an important mechanism of oncogenesis. Although previous studies have reported an inverse association between levels of autophagy and malignant transformation (reviewed in refs. 31, 71), our findings directly demonstrate that genetic inactivation of an autophagy-execution gene promotes tumorigenesis. Furthermore, since beclin 1 is monoallelically deleted in a high percentage of human sporadic breast and ovarian cancers (reviewed in ref. 29), the demonstration of a haplo-insufficient tumorsuppressor phenotype of beclin 1 in mice may have direct implications for the role of such genetic alterations in the molecular pathogenesis of human cancer.

\section{Acknowledgments}

We thank Riccardo Dalla-Favera and Laura Pasqualucci for helpful discussions, Francis Chisari and Tamotsu Yoshimori for providing critical reagents, Robin Chamberlain for administrative assistance, the Experimental Molecular Pathology Core Facility of the Herbert Irving Comprehensive Cancer Center for providing histology sections, and Kristy Brown for providing electron microscopy sections. This work was supported by NIH grants RO1 AI44157, RO1 CA84254, and ACS RSG-339 (B. Levine); a Mallinckrodt Scholar Award (B. Levine); an Esther Aboodi Associate Professorship (G. Cattoretti); and NIH grant RO1 CA16303 (J. Rosen).

1. Spataro, V., Norbury, C., and Harris, A.L. 1998. The ubiquitin-proteasome pathway in cancer. Br. J. Cancer. 77:448-455.

2. Elliott, P.J., and Ross, J.S. 2001. The proteasome: a new target for novel drug therapies. Am. J. Clin. Pathol. 116:637-646.

3. Richardson, P. 2003. Clinical update: proteasome inhibitors in hematologic malignancies. Cancer Treat. Rev. 29(Suppl. 1):33-39.

4. Lenz, H.J. 2003. Clinical update: proteasome inhibitors in solid tumors. Cancer Treat. Rev. 29(Suppl. 1):41-48.

5. Bursch, W., et al. 1996. Active cell death induced by the anti-estrogens tamoxifen and ICI 164384 in human mammary carcinoma cells (MC7-7) in culture: the role of autophagy. Carcinogenesis. 17:1595-1607.

6. Noda, T., and Ohsumi, Y. 1998. Tor, a phosphatidylinositol kinase homologue, controls autophagy in yeast. J. Biol. Chem. 273:3963-3966.
7. Dunn, W.A.J. 1994. Autophagy and related mechanisms of lysosomemediated protein degradation. Trends Cell Biol. 4:139-143.

8. Klionsky, D.J., and Emr, S.D. 2000. Autophagy as a regulated pathway of cellular degradation. Science. 290:1717-1721.

9. Klionsky, D.J. 2003. Autophagy. Landes Bioscience. Georgetown, Texas, USA. 307 pp.

10. Gunn, J.M., Clark, M.G., Knowles, S.E., Hopgood, M.F., and Ballard, F.J. 1977. Reduced rates of proteolysis in transformed cells. Nature. 266:58-60.

11. Otsuka, H., and Moskowitz, M. 1978. Differences in the rates of protein degradation in untransformed and transformed cell lines. Exp. Cell Res. 112:127-135.

12. Knecht, E., Hernandez-Yago, J., and Grisolia, S. 1984. Regulation of lysosomal autophagy in transformed and non-transformed mouse fibroblasts under several growth conditions. Exp. Cell Res. 154:224-232.

13. Kopitz, J., Kisen, G.O., Gordon, P.B., Bohley, P., and Seglen, P.O. 1990 Nonselective autophagy of cytosolic enzymes by isolated rat hepatocytes. J. Cell Biol. 111:941-953.

14. Kisen, G.O., et al. 1993. Reduced autophagic activity in primary rat hepatocellular carcinoma and ascites hepatoma cells. Carcinogenesis. 14:2501-2505.

15. Tsukada, M., and Ohsumi, Y. 1993. Isolation and characterization of autophagy-defective mutants of Saccharomyces cerevisiae. FEBS Lett. 333:169-174.

16. Thumm, M., et al. 1994. Isolation of autophagocytosis mutants of Saccharomyces cerevisiae. FEBS Lett. 349:275-280.

17. Liang, X.H., et al. 1998. Protection against fatal Sindbis virus encephalitis by Beclin, a novel Bcl-2-interacting protein. J. Virol. 72:8586-8596.

18. Kametaka, S., Okano, T., Ohsumi, M., and Ohsumi, Y. 1998. Apg14p and Apg6/Vps30p form a protein complex essential for autophagy in the yeast, Saccharomyces cerevisiae. J. Biol. Chem. 273:22284-22291.

19. Liang, X.H., et al. 1999. Induction of autophagy and inhibition of tumorigenesis by beclin 1. Nature. 402:672-676.

20. Kihara, A., Kabeya, Y., Ohsumi, Y., and Yoshimori, T. 2001. Beclin-phosphatidylinositol 3-kinase complex functions at the trans-Golgi network EMBO Rep. 2:330-335.

21. Russell, S.E., Hickey, G.I., Lowry, W.S., White, P., and Atkinson, R.J. 1990. Allele loss from chromosome 17 in ovarian cancer. Oncogene. 5:1581-1583.

22. Eccles, D.M., et al. 1992. Early loss of heterozygosity on $17 \mathrm{q}$ in ovarian cancer. Oncogene. 7:2069-2072.

23. Cliby, W., et al. 1993. Human epithelial ovarian cancer allelotype. Cancer Res. 53:2393-2398.

24. Tangir, J., et al. 1996. A $400 \mathrm{~kb}$ novel deletion unit centromeric to the BRCA1 gene in sporadic epithelial ovarian cancer. Oncogene. 12:735-740.

25. Futreal, P.A., et al. 1992. Detection of frequent allelic loss on proximal chromosome $17 \mathrm{q}$ in sporadic breast carcinoma using microsatellite length polymorphisms. Cancer Res. 52:2624-2627.

26. Saito, H., et al. 1993. Detailed deletion mapping of chromosome $17 \mathrm{q}$ in ovarian and breast cancers: 2 -cM region on $17 \mathrm{q} 21.3$ often and commonly deleted in tumors. Cancer Res. 53:3382-3385.

27. Gao, X., et al. 1995. Loss of heterozygosity of the BRCA1 and other loci on chromosome $17 \mathrm{q}$ in human prostate cancer. Cancer Res. 55:1002-1005.

28. Knudson, A.G.J. 1971. Mutation and cancer: statistical study of retinoblastoma. Proc. Natl. Acad. Sci. U. S. A. 68:820-823.

29. Aita, V.M., et al. 1999. Cloning and genomic organization of beclin 1, a candidate tumor suppressor gene on chromosome $17 \mathrm{q} 21$. Genomics. 59:59-65

30. Liang, X.H., Yu, J., Brown, K., and Levine, B. 2001. Beclin 1 contains a leucine-rich nuclear export signal that is required for its autophagy and tumor suppressor function. Cancer Res. 61:3443-3449.

31. Furuya, N., Liang, X.H., and Levine, B. 2003. Autophagy and cancer. In Autophagy. D.J. Klionsky, editor. Landes Bioscience. Georgetown, Texas, USA. 244-253.

32. Mouse Tumor Biology Database. http://tumor.informatics.jax.org/ FMPro?-db=Source\&-format=strain_search.html\&-view.

33. Chisari, F.V., et al. 1989. Molecular pathogenesis of hepatocellular carcinoma in hepatitis B virus transgenic mice. Cell. 59:1145-1156.

34. Morse, H.C., et al. 2002. Bethesda proposals for classification of lymphoid neoplasms in mice. Blood. 100:246-258.

35. Bessler, M., et al. 2002. Glycosylphosphatidylinositol-linked proteins are required for maintenance of a normal peripheral lymphoid compartment but not for lymphocyte development. Eur. J. Immunol. 32:2607-2616.

36. Shyamala, G., Yang, X., Silberstein, G., Barcellos-Hoff, M.H., and Dale, E. 1998. Transgenic mice carrying an imbalance in the native ratio of $A$ to B forms of progesterone receptor exhibit developmental abnormalities in mammary glands. Proc. Natl. Acad. Sci. U. S. A. 95:696-701.

37. Cardiff, R.D., et al. 2000. The mammary pathology of genetically engineered mice: the consensus report and recommendations from the Annapolis meeting. Oncogene. 19:968-988. 
38. Rose, M.L., Birbeck, M.S., Wallis, V.J., Forrester, J.A., and Davies, A.J. 1980. Peanut lectin binding properties of germinal centres of mouse lymphoid tissues. Nature. 284:364-366.

39. Flano, E., Kim, I.-J., Woodland, D.L., and Blackman, M.A. 2002. $\gamma$-Herpesvirus latency is preferentially maintained in splenic germinal center and memory B cells. J. Exp. Med. 196:1363-1372.

40. Talloczy, Z., et al. 2002. Regulation of starvation- and virus-induced autophagy by the eIF2alpha kinase signaling pathway. Proc. Natl. Acad. Sci. U. S. A. 99:190-195.

41. Weibel, E.R. 1969. Stereological principles for morphometry in electron microscopic cytology. Int. Rev. Cytol. 26:235-302.

42. Ikeda, K., et al. 1995. Gene structure and expression of human thyroid transcription factor-1 in respiratory epithelial cells. J. Biol. Chem. 270:8108-8114.

43. Kitamura, H., Kameda, Y., Ito, T., and Hayashi, H. 1999. Atypical adenomatous hyerplasia of the lung. Implications for the pathogenesis of peripheral lung adenocarcinoma. Am. J. Clin. Pathol. 111:610-622.

44. Dalla-Favera, R., et al. 1999. Molecular pathogenesis of B cell malignancy: the role of BCL-6. Curr. Top. Microbiol. Immunol. 246:257-263.

45. Malek, S.N., Dordai, D.I., Reim, J., Dintzis, H., and Desiderio, S. 1998 Malignant transformation of early lymphoid progenitors in mice expressing an activated Blk tryosine kinase. Proc. Natl. Acad. Sci. U. S. A. 95:7351-7356.

46. Jolly, C.J., Klix, N., and Neuberger, M.S. 1997. Rapid methods for the analysis of immunoglobulin gene hypermutation: application to transgenic and gene targeted mice. Nucleic Acids Res. 25:1913-1919.

47. Blommaart, E.F., Luiken, J.J., and Meijer, A.J. 1997. Autophagic proteolysis: control and specificity. Histochem. J. 29:365-385.

48. Hu, J.-F., et al. 1997. Repression of hepatitis B virus (HBV) transgene and HBV-induced liver injury by low protein diet. Oncogene. 15:2795-2801.

49. Kojiro, M. 2000. Premalignant lesions of hepatocellular carcinoma: pathologic viewpoint. J. Hepatobiliary Pancreat. Surg. 7:535-541.

50. Terasaki, S., Kaneko, S., Kobayashi, K., Nonomura, A., and Nakanuma, Y. 1998. Histological features predicting malignant transformation of nonmalignant hepatocellular nodules: a prospective study. Gastroenterology. 115:1216-1222.

51. Libbrecht, L., Craninx, M., Nevens, F., Desmet, V., and Roskams, T. 2001. Predictive value of liver cell dysplasia for development of hepatocellular carcinoma in patients with non-cirrhotic and cirrhotic chronic viral hepatitis. Histopathology. 39:66-73.

52. Melendez, A., et al. 2003. Autophagy genes are essential for dauer development and lifespan extension in C. elegans. Science. 301:1387-1391.

53. Seaman, M.N., Marcusson, E.G., Cereghino, J.L., and Emr, S.D. 1997. Endosome to Golgi retrieval of the vacuolar protein sorting receptor, Vps10p, requires the function of the VPS29, VPS30, and VPS35 gene products. J. Cell Biol. 137:79-92.

54. Kihara, A., Noda, T., Ishihara, N., and Ohsumi, Y. 2001. Two distinct Vps34 phosphatidylinositol 3-kinase complexes function in autophagy and carboxypeptidase Y sorting in Saccharomyces cerevisiae. J. Cell Biol. 152:519-530.
55. Kirisako, T., et al. 1999. Formation process of autophagosome is traced with Apg8/Aut7p in yeast. J. Cell Biol. 147:435-446.

56. Huang, W.-P., Scott, S.V., Kim, J., and Klionsky, D.J. 2000. The itinerary of a vesicle component, Aut $7 \mathrm{p} / \mathrm{Cvt} 5 \mathrm{p}$, terminates in the yeast vacuole vis the autophagy/cvt pathways. J. Biol. Chem. 275:5845-5851.

57. Kabeya, Y., et al. 2000. LC3, a mammalian homologue of yeast Apg8p, is localized in autophagosome membranes after processing. EMBO J. 19:5720-5728.

58. Suzuki, K., et al. 2001. The pre-autophagosomal structure organized by concerted functions of APG genes is essential for autophagosome formation. EMBO J. 20:5971-5981.

59. Kim, J., Huang, W.P., Stromhaug, P.E., and Klionsky, D.J. 2002. Convergence of multiple autophagy and cytoplasm to vacuole targeting components to a perivacuolar membrane compartment prior to de novo vesicle formation. J. Biol. Chem. 277:763-773.

60. Fero, M.L., Randel, E., Gurley, K.E., Roberts, J.M., and Kemp, C.J. 1998. The murine gene $\mathrm{p} 27^{k i p 1}$ is haplo-insufficient for tumour suppression. Nature. 396:177-180

61. Petiot, A., Ogier-Denis, E., Blommaart, E.F., Meijer, A.J., and Codogno, P. 2000. Distinct classes of phosphatidylinositol 3'-kinases are involved in signaling pathways that control macroautophagy in HT-29 cells. J. Biol. Chem. 275:992-998.

62. Arico, S., et al. 2001. The tumor suppressor PTEN positively regulates macroautophagy by inhibiting the phosphatidylinositol 3-kinase/protein kinase B pathway. J. Biol. Chem. 276:35243-35246.

63. Cutler, N.S., Heitman, J., and Cardenas, M.E. 1999. TOR kinase homologs function in a signal transduction pathway that is conserved from yeast to mammals. Mol. Cell. Endocrinol. 155:135-142.

64. Podsypanina, K., et al. 2001. An inhibitor of mTOR reduces neoplasia and normalizes p70/S6 kinase activity in Pten ${ }^{+/-}$mice. Proc. Natl. Acad. Sci. U. S. A. 98:10320-10325.

65. Huang, S., and Houghton, P.J. 2002. Inhibitors of mammalian target of rapamycin as novel antitumor agents: from bench to clinic. Curr. Opin. Investig. Drugs. 3:295-304.

66. Elit, L. 2002. CCI-779 Wyeth. Curr. Opin. Investig. Drugs. 3:1249-1253.

67. Tanaka, K., and Ichihara, A. 1978. Effect of the growth state on protein turnover in two lines of cultured BHK cells. J. Cell. Physiol. 93:407-416.

68. Hendil, K.B. 1977. Intracellular protein degradation in growing, in density-inhibited, and in serum-restricted fibroblast cultures. J. Cell. Physiol. 92:353-364.

69. Amenta, J.S., Sargus, M.J., Venkatesan, S., and Shinozuka, H. 1978. Role of the vacuolar apparatus in augmented protein degradation in cultured fibroblasts. J. Cell. Physiol. 94:77-86.

70. Amenta, J.S., Sargus, M.J., and Brocher, S.C. 1980. Protein synthesis and degradation in growth regulation in rat embryo fibroblasts: role of fast turnover and slow-turnover protein. J. Cell. Physiol. 105:51-61.

71. Ogier-Denis, E., and Codogno, P. 2003. Autophagy: a barrier or an adap tive response to cancer? Biochim. Biophys. Acta. 1603:113-128.

72. Watanabe, S., et al. 1983. Morphologic studies of the liver cell dysplasia. Cancer. 51:2197-2205 